Research Article

\title{
Comparison of efficacy, safety and cost-effectiveness of clotrimazole 1\% cream and sertaconazole $2 \%$ cream in patients suffering from of mild to moderate tinea corporis, attending tertiary care hospital out-patient department: a randomized, open-labeled, comparative, parallel group trial
}

\author{
Huma S. Khan ${ }^{1 *}$, Sujata Dudhgaonkar ${ }^{1}$, M. M. Bende ${ }^{2}$, Sumit Wankhede ${ }^{1}$
}

\begin{abstract}
${ }^{1}$ Department of Pharmacology, Indira Gandhi Government Medical College, Nagpur, Maharashtra, India, ${ }^{2}$ Department of Pharmacology, Shri Vasantrao Naik Government Medical College, Yavatmal, Maharashtra, India
\end{abstract}

Received: 05 December 2014 Accepted: 19 December 2014

\author{
*Correspondence to: \\ Dr. Huma S. Khan, \\ Email: humakhan080@gmail. \\ com
}

\section{Copyright: (C) the author(s), publisher and licensee Medip Academy. This is an open- access article distributed under the terms of the Creative Commons Attribution Non- Commercial License, which permits unrestricted non- commercial use, distribution, and reproduction in any medium, provided the original work is properly cited.}

\begin{abstract}
Background: Tinea corporis is a common dermatophytic infection of the body involving keratin layer of skin. This lesion presents as an annular plaque with an advancing border along with central clearing. Clotrimazole is topical, conventional imidazole antifungal drug and has given good efficacy in tinea corporis. Sertaconazole is new topical imidazole antifungal claimed to be superior to old topical imidazoles in tinea corporis. The aim of this study was to compare efficacy, safety and cost effectiveness of topical antifungals, clotrimazole $1 \%$ cream and sertaconazole $2 \%$ cream in patients suffering from mild to moderate tinea corporis attending out-patient department of tertiary care hospital in Vidarbha region of Maharashtra.

Methods: This was a prospective, comparative, randomized trial with 2 parallel treatment arms of 4 weeks duration. Patients were diagnosed on the basis of clinical evaluation and microscopic findings of $\mathrm{KOH}$ mount. Hundred patients were randomly assigned into two groups of clotrimazole $1 \%$ cream, and sertaconazole $2 \%$ cream with 50 patients in each group. Evaluation was carried out at baseline, $1^{\text {st }}$ week, $2^{\text {nd }}$ week and $4^{\text {th }}$ week for efficacy parameters viz. itching, erythema and scaling, physician's global assessment (PGA), safety and cost effectiveness.

Results: Topical sertaconazole $2 \%$ cream was highly efficacious and superior to clotrimazole $1 \%$ cream in improvement of clinical parameters, PGA and mycological cure at the end of the treatment phase. At end of the follow-up phase both the trial drugs were effective with no recurrence or relapse of tinea corporis. However, clotrimazole $1 \%$ cream was safe and cheaper.

Conclusions: Topical clotrimazole $1 \%$ cream and sertaconazole $2 \%$ were effective and well tolerated in patients of tinea corporis. Effectiveness of sertaconazole was early and superior with tolerable side-effects. However, clotrimazole was costeffective.
\end{abstract}

Keywords: Tinea corporis, Clotrimazole, Sertaconazole, Cost effectiveness

\section{INTRODUCTION}

"Dermatophytoses" are fungal infections caused by dermatophytes belonging to genera of trichophyton, microsporum, and epidermatophyton; a group of fungi that invade and grow in keratin of skin, hair, and nail. In India, the most commonly occurring clinical type of dermatophytoses includes tinea corporis (36-59\%) and tinea cruris (12-27\%). ${ }^{1,2}$ Tinea corporis refers to tinea anywhere on the body except the scalp, beard, feet, hands, groin, and nails. The incidence of fungal infections is increasing due to widespread use of antimicrobials and immune-suppressants and due to immune-compromised states such as diabetes mellitus, HIV-AIDS etc. ${ }^{3,4}$ Both topical and systemic therapies may be used to treat dermatophytic infections. The oral drugs show poor compliance because of the length of treatment, side effects and cost.

Clotrimazole have been widely used topically for the treatment of the superficial dermatophytosis for over 25 years. It is a broad spectrum antifungal agent that is used for the treatment of dermal infections caused by various 
species of dermatophytes, yeasts, and Malassezia furfur. ${ }^{5,6}$ Sertaconazole nitrate is the new topical azole antifungal, found to be more effective than conventional azoles. This recently developed antifungal is characterized by broad spectrum of action against yeasts, dermatophytes and Gram-positive bacteria as well. ${ }^{7,8}$ We came across no trials reported in the literature comparing efficacy, safety and cost effectiveness of topical antifungals clotrimazole and sertaconazole in the treatment of tinea corporis.

Hence, this study was undertaken to compare two antifungals, the established medicine clotrimazole and the most recently introduced sertaconazole in patients suffering from tinea corporis of Vidarbha region of the central India, based on efficacy, safety and cost effectiveness.

\section{METHODS}

This was a prospective, comparative, randomized, openlabeled, controlled, parallel group study. Totally 100 patients satisfying inclusion criteria were selected at skin out-patient department of tertiary center and randomized in a 1:1 ratio into two groups, each of 50 patients. One group was treated with topical clotrimazole $1 \%$ cream while other received topical sertaconazole $2 \%$ cream after approval from Institutional Ethics Committee.

\section{Selection of participants}

The patients of both genders in age group of 18-65 years, having clinical manifestations of mild to moderate tinea corporis and positive for $\mathrm{KOH}$ mount were selected. Patients with systemic mycosis or mycosis of the hands, groin, nails, feet, face and scalp, those received antifungals and immunosuppressive medicines within last 1 month, prior to the onset of study, pregnant and nursing mothers and patients with history of diabetes mellitus and other systemic illness were excluded.

The duration of the study was 4 weeks consisting of two phases; initial "treatment phase" consisted first 2 weeks and "follow-up phase" for next 2 weeks. After a detailed history, general and systemic examination, clinical assessment was done based on parameters of itching, erythema and scaling at base line, $1^{\text {st }}$ week, $2^{\text {nd }}$ week and $4^{\text {th }}$ week. Furthermore, physician's global assessment (PGA) was rated on 4 point scale as poor, satisfactory, good and excellent. Mycological examination was done with $\mathrm{KOH}$ mount of skin scrapings. Absence of fungal elements was considered as mycological cure.

\section{Efficacy outcome}

\section{Primary efficacy outcome}

The primary efficacy outcome was clinical cure at the end of "treatment phase" and "follow-up Phase," which included parameters itching, erythema and scaling, and graded as absent (0), mild (1), moderate (2) and severe (3). ${ }^{9}$

\section{Secondary efficacy outcome}

The secondary efficacy outcome was mycological cure.

\section{Safety assessment}

The safety of the therapy was monitored by follow-up visits of patients for the emergent of adverse events if any.

\section{Cost-effectiveness analysis}

For the calculation of cost effectiveness, direct cost of the therapy was considered. It was calculated by calculating fingertip units (FTU); ${ }^{10}$ one FTU is equal to $0.5 \mathrm{~g}$ of cream, if the lumen of the tube has diameter of $5 \mathrm{~mm}$. Efficacy outcome parameter was PGA. Cost-effectiveness ratio was calculated by dividing cost with outcome. ${ }^{11}$

\section{Statistical analysis}

Sample size was rounded to 100 considering future drop outs. Results were expressed as mean \pm standard error of the mean. Categorical variable was expressed in actual numbers and percentage. Parametric test used was unpaired t-test. Differences within group were compared by Friedman test with Dunn's multiple comparison post-hoc test. Group differences were ascertained by Mann-Whitney Rank Sum test. Two tailed $\mathrm{p}<0.05$ was considered as statistically significant.

\section{RESULTS}

In the study total, 100 patients underwent randomization and included in the intention to treat groups. Two groups were balanced with respect to baseline characteristics (Table 1). There were total 5 cases who lost to follow-up, 3 in clotrimazole group and 2 in sertaconazole group. The reason of drop outs was failure of the patient to report in follow-up phase after completion of the treatment phase.

Table 1 shows the comparison of baseline demographic characteristics and clinical features of itching, erythema and scaling in treatment groups of clotrimazole $1 \%$ cream and sertaconazole $2 \%$ cream. There was no statistically significant difference in the mean scores of these parameters in both the treatment groups.

Table 2 shows the intra-group comparison of the efficacy of clotrimazole $1 \%$ cream and sertaconazole $2 \%$ cream on itching, erythema and scaling at $1^{\text {st }}, 2^{\text {nd }}$ and $4^{\text {th }}$ week. At $1^{\text {st }}$ week of follow-up, in clotrimazole group the reduction in mean scores of itching and scaling was statistically significant $(p<0.01$ in itching and $p<0.05$ in scaling) and nonsignificant of erythema, whereas it was highly significant $(p<0.001)$ in sertaconazole group when compared to baseline scores. The reduction in mean scores of itching, erythema 
and scaling was statistically highly significant $(p<0.001)$ in both the treatment groups at the $2^{\text {nd }}$ and $4^{\text {th }}$ week when compared with the scores of baseline and $1^{\text {st }}$ week. However, no significant difference was found when $2^{\text {nd }}$ week was compared to $4^{\text {th }}$ week in both the treatment groups. Both the trial drugs achieved complete clinical cure at the end of $4^{\text {th }}$ week.

Table 3 shows the inter-group comparison of mean difference of itching, erythema and scaling scores at $1^{\text {st }}$ week, $2^{\text {nd }}$ week and $4^{\text {th }}$ week from the baseline score in treatment groups of clotrimazole $1 \%$ cream and sertaconazole $2 \%$ cream. It was found that the mean difference of itching, erythema and scaling was statistically highly significant $(p<0.001)$ in sertaconazole group when compared with clotrimazole group at the end of $1^{\mathrm{st}}$ week. The mean difference of baseline to $2^{\text {nd }}$ week's score was highly significant $(p<0.001)$ in itching, significant $(\mathrm{p}<0.05)$ in erythema and statistically non-significant in scaling when sertaconazole $2 \%$ cream was compared with clotrimazole $1 \%$ cream. However mean difference of the baseline to $4^{\text {th }}$ week's score was statistically

Table 1: Baseline demographic data and clinical characteristics of patients.

\begin{tabular}{|c|c|c|}
\hline Characteristic & Clotrimazole & Sertaconazole \\
\hline $\begin{array}{l}\text { Number of patients } \\
\text { recruited }\end{array}$ & 50 & 50 \\
\hline $\begin{array}{l}\text { Number of patients } \\
\text { completed trial }\end{array}$ & 47 & 48 \\
\hline Age (years) & $37.06 \pm 1.55$ & $38.02 \pm 1.22$ \\
\hline \multicolumn{3}{|l|}{ Gender } \\
\hline Male & 33 & 30 \\
\hline Female & 17 & 20 \\
\hline Height (cm) & $158.6 \pm 1.00$ & $159.7 \pm 1.22$ \\
\hline Weight (kg) & $60.4 \pm 0.89$ & $60.8 \pm 1.25$ \\
\hline Itching & $2.72 \pm 0.07$ & $2.70 \pm 0.07$ \\
\hline Erythema & $2.45 \pm 0.1$ & $2.64 \pm 0.08$ \\
\hline Scaling & $2.57 \pm 0.07$ & $2.5 \pm 0.09$ \\
\hline
\end{tabular}

Values are expressed as mean \pm SEM. SEM: Standard error of the mean significant for erythema, but non-significant for itching and scaling the score when the two trial drugs were compared. This shows that sertaconazole $2 \%$ cream was significantly superior in efficacy when compared with clotrimazole $1 \%$ cream.

Figure 1 shows the comparison of PGA of patients suffering from mild to moderate tinea corporis at the end of $1^{\text {st }}$ week in treatment groups of clotrimazole $1 \%$ cream and sertaconazole $2 \%$ cream. It was observed that with clotrimazole $1 \%$ cream, response was poor in $21.2 \%$ cases, satisfactory in $63.8 \%$ cases and good in $14.8 \%$ cases. Whereas with sertaconazole $2 \%$ cream, response was poor only in $4 \%$ cases, satisfactory in $64.5 \%$ cases and good in $31.25 \%$ cases.

Figure 2 shows the comparison of PGA of patients suffering from mild to moderate tinea corporis at the end of "treatment phase" in treatment groups of clotrimazole $1 \%$ cream and sertaconazole $2 \%$ cream. It was observed that with clotrimazole $1 \%$ cream, response was good in $25.53 \%$ cases, whereas with sertaconazole $2 \%$ cream, response was good in $6.25 \%$ cases.

Complete clinical cure i.e. excellent response at the end of "treatment phase" was observed in $93.75 \%$ of patients in sertaconazole group and $74.47 \%$ patients of clotrimazole

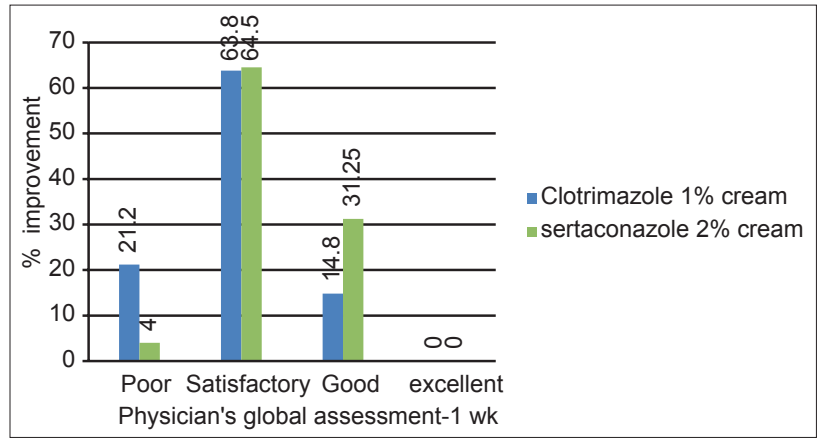

Figure 1: The comparison of physician's global assessment of patients, suffering from mild to moderate tinea corporis at the end of $1^{\text {st }}$ week.

Table 2: Within group comparison of mean scores of itching, erythema and scaling at baseline, $1^{\text {st }}$ week, $2^{\text {nd }}$ week and $4^{\text {th }}$ week in clotrimazole and sertaconazole groups.

\begin{tabular}{|c|c|c|c|c|}
\hline Parameter & Baseline & $1^{\text {st }}$ week & $2^{\text {nd }}$ week & $4^{\text {th }}$ week \\
\hline \multicolumn{5}{|c|}{ Clotrimazole $(n=47)$} \\
\hline Itching & $2.73 \pm 0.06$ & $1.69 \pm 0.06^{* *}$ & $0.60 \pm 0.07 * * *$ & $0.19 \pm 0.05^{* * *}$ \\
\hline Erythema & $2.42 \pm 0.01$ & $1.97 \pm 0.11$ & $0.21 \pm 0.06^{* * *}$ & $0.08 \pm 0.04 * * *$ \\
\hline Scaling & $2.57 \pm 0.07$ & $1.85 \pm 0.05^{*}$ & $0.36 \pm 0.07 * * *$ & $0.19 \pm 0.05^{* * *}$ \\
\hline \multicolumn{5}{|c|}{ Sertaconazole $(n=48)$} \\
\hline Itching & $2.70 \pm 0.07$ & $1.10 \pm 0.08 * * *$ & $0.041 \pm 0.02 * * *$ & $0 * * *$ \\
\hline Erythema & $2.65 \pm 0.08$ & $1.08 \pm 0.09 * * *$ & $0.08 \pm 0.04 * * *$ & $0 * * *$ \\
\hline Scaling & $2.5 \pm 0.1$ & $1.08 \pm 0.1 * * *$ & $0.08 \pm 0.04 * * *$ & $0 * * *$ \\
\hline
\end{tabular}

Values are expressed as mean \pm SEM; Friedman test with Dunn's multiple comparison post-hoc test. $* * * \mathrm{p}<0.001, * * \mathrm{p}<0.01,{ }^{*} \mathrm{p}<0.05$. SEM: Standard error of the mean 
Table 3: Inter group comparison of mean differences of scores of itching, erythema and scaling at $1^{\text {st }}, 2^{\text {nd }}$ and $4^{\text {th }}$ week from baseline score in clotrimazole and sertaconazole groups.

\begin{tabular}{|c|c|c|c|c|c|c|}
\hline \multirow{2}{*}{$\begin{array}{l}\text { Duration } \\
\text { Parameters }\end{array}$} & \multicolumn{2}{|c|}{ Baseline to $1^{\text {st }}$ week } & \multicolumn{2}{|c|}{ Baseline to $2^{\text {nd }}$ week } & \multicolumn{2}{|c|}{ Baseline to $4^{\text {th }}$ week } \\
\hline & Clotrimazole & Sertaconazole & Clotrimazole & Sertaconazole & Clotrimazole & Sertaconazole \\
\hline Itching & $1.02 \pm 0.06$ & $1.6 \pm 0.09 * * *$ & $2.1 \pm 0.07$ & $2.66 \pm 0.07 * * *$ & $2.53 \pm 0.08$ & $2.71 \pm 0.07$ \\
\hline Erythema & $0.45 \pm 0.08$ & $1.56 \pm 0.54 * * *$ & $2.21 \pm 0.1$ & $2.56 \pm 0.08 *$ & $2.34 \pm 0.1$ & $2.64 \pm 0.08^{*}$ \\
\hline Scaling & $0.72 \pm 0.06$ & $1.41 \pm 0.1 * * *$ & $2.21 \pm 0.1$ & $2.41 \pm 0.09$ & $2.39 \pm 0.1$ & $2.5 \pm 0.09$ \\
\hline
\end{tabular}

Values are expressed as mean \pm SEM; Mann-Whitney Rank Sum test, ${ }^{*} p<0.05$ and $* * * p<0.001$. SEM: Standard error of the mean

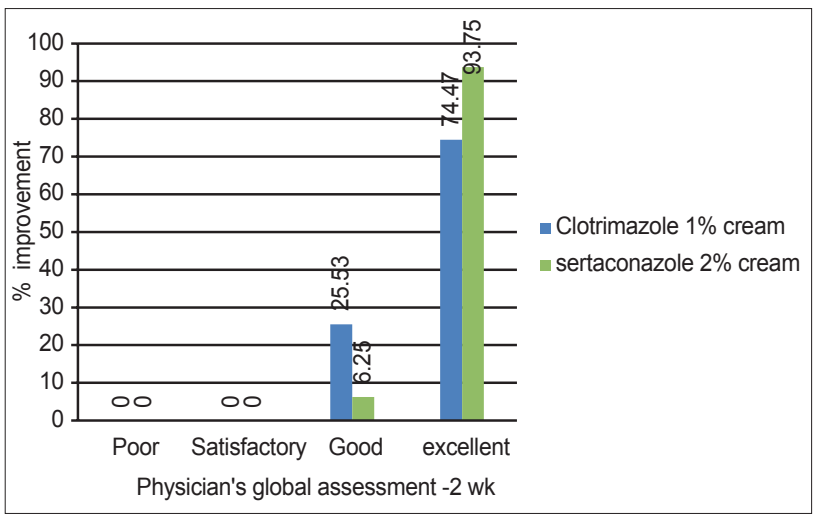

Figure 2: The comparison of physician's global assessment of patients, suffering from mild to moderate tinea corporis at the end of "treatment phase".

group which proves that sertaconazole $2 \%$ cream had a cure rate superior to clotrimazole $1 \%$ cream. At the end of "follow-up" phase both the groups showed $100 \%$ cure rate. There was absence of any relapse recurrence of the disease with both the trial drugs.

Figure 3 shows the comparison of percentage of positive cases for fungal elements on $\mathrm{KOH}$ mount in patients suffering from mild to moderate tinea corporis at baseline, end of "treatment phase" and "follow-up phase" in treatment groups of clotrimazole $1 \%$ cream and sertaconazole $2 \%$ cream. It was observed that at baseline $100 \%$ cases were positive on mycological examination. At the end of "treatment phase" $38 \%$ and $6 \%$ cases were positive in clotrimazole and sertaconazole groups respectively. At the end of "follow-up phase" there was no $(0 \%)$ positive case in both the treatment groups.

At the end of "treatment phase" complete mycological cure was observed in $94 \%$ patients treated with sertaconazole $2 \%$ cream and in $62 \%$ patients treated with clotrimazole $1 \%$ cream. At the end of "follow-up" phase both the drugs showed $100 \%$ cure with absence of any relapse and recurrence.

\section{Safety analysis of therapy}

Clotrimazole $1 \%$ cream and sertaconazole $2 \%$ cream were well tolerated with mild application site adverse drug reactions (ADR). No severe adverse events were reported, no participants from the study discontinued due to ADR and no case of non-compliance to the therapy was reported.

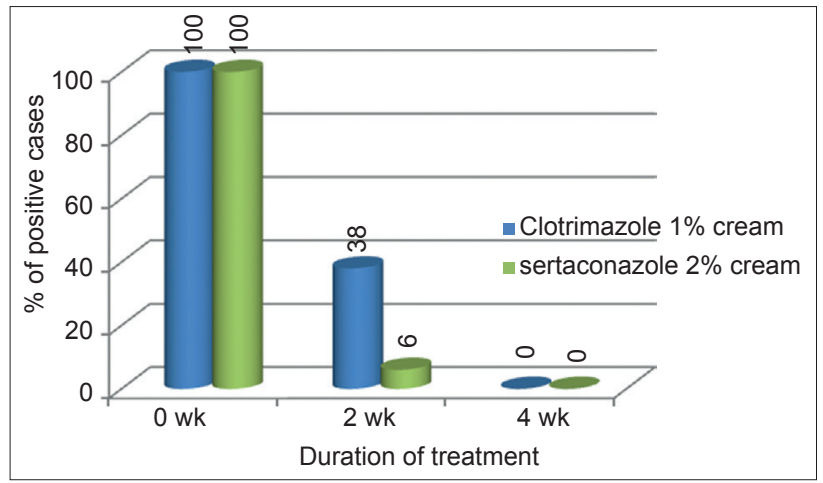

Figure 3: The comparison of percentage of positive cases for fungal elements on $\mathrm{KOH}$ mount in patients suffering from mild to moderate tinea corporis at baseline, end of "treatment phase" and "follow-up phase".

One ADR related to treatment of sertaconazole $2 \%$ cream during the $1^{\text {st }}$ week was burning the sensation at the site of application of drug.

For assessing the cost-effectiveness, amount of topical drug needed was calculated by averaging requirement for different sites, which came out as two tubes per week of $15 \mathrm{~g}$ each. Thus, the average cost of treatment with clotrimazole $1 \%$ cream, at the end of "treatment phase" and "follow-up phase" week was INR 92 and INR 184 respectively and with sertaconazole 2\% cream, it was INR 420 and INR 840, respectively. Efficacy outcome parameter was PGA. Figure 4 shows that CER of sertaconazole $2 \%$ cream was statistically highly significant when compared with clotrimazole $1 \%$ cream at end of "treatment phase" and at the end of "follow-up phase." The CER was higher for sertaconazole $2 \%$ cream, followed by clotrimazole $1 \%$ cream at both the follow ups.

\section{DISCUSSION}

Tinea corporis is a common superficial fungal infection occuring in tropical countries, commonly known as "ringworm." Usually, there is a trend towards prescribing combinations of antifungals, corticosteroids and antimicrobials for the treatment of common fungal skin infections without confirming the diagnosis leading to risk of side effects, resistance, excessive cost etc. Efficacy of monotherapy with topical antifungals in the treatment of tinea corporis is controversial due to few studies. Hence, the present study was carried out. 


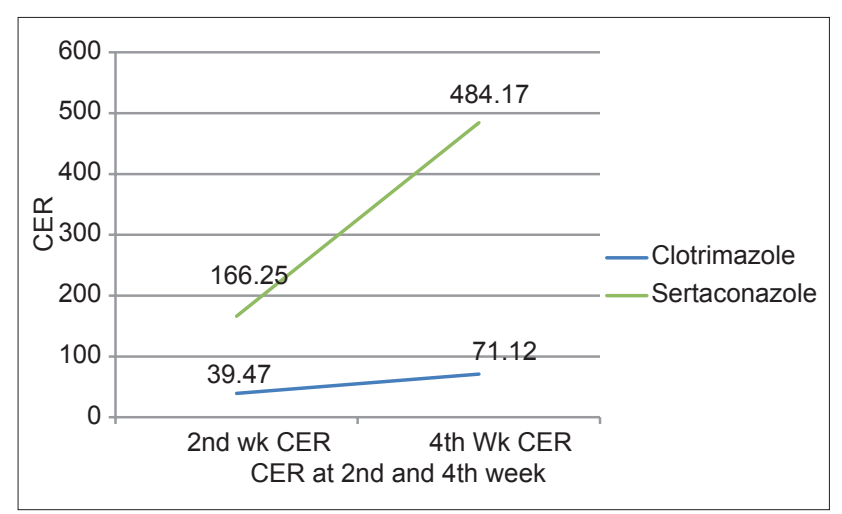

Figure 4: The comparison of mean of cost effectiveness ratio of clotrimazole $1 \%$ cream and sertaconazole $2 \%$ cream at the end of "treatment phase" and "follow-up phase".

Total hundred patients of both genders were included in the study. The baseline demographic data and clinical characteristics of participants of the study were matching. This proves the homogeneity of our study subjects in the two groups. Most patients were in the age group of 29-46 years. ${ }^{2,12-14}$ The percentage of male patients with fungal infection was more than women patients i.e. $63 \%$ including both groups, ${ }^{2,12,15}$ may be due to higher exposure to sun and heat, schools or colleges, jobs and sporting activities leads to excessive sweating, warm and moist skin; a good medium for the fungal growth. . $2,12,15$

The effect of topical therapies with clotrimazole $1 \%$ cream and sertaconazole $2 \%$ cream, twice daily application for 4 weeks was compared in patients suffering from mild to moderate tinea corporis. The initial 2 weeks were "treatment phase" where clinical and mycological outcome was evaluated, and last 2 weeks were "follow-up phase" where recurrence and relapse of tinea corporis were observed.

In the present study based on data of 100 evaluable patients, both the study drugs showed a significant reduction in clinical features (itching, erythema and scaling) of tinea corporis as compared to baseline. ${ }^{16-18}$ However, response to therapy was early in onset and higher in sertaconazole group. At end of " treatment phase," significantly higher proportion of patients treated with topical sertaconazole $2 \%$ cream had improvement of itching, erythema, and scaling as compared to clotrimazole $1 \%$ cream.

The probable superiority of sertaconazole $2 \%$ cream over clotrimazole $1 \%$ cream may be attributed to its wide range of mechanism of action, described as follows.

Fungistatic activity is resulting from interference with ergosterol synthesis, an essential component of the fungal cell membrane, inhibition of its synthesis results in increased cellular permeability causing leakage of cellular contents. It is a highly selective inhibitor of fungal cytochrome P-450 sterol C-14 $\alpha$-demethylation via the inhibition of the enzyme cytochrome P450 $14 \alpha$-demethylase. This enzyme converts lanosterol to ergosterol and is required in fungal cell wall synthesis. The subsequent loss of normal sterols correlates with the accumulation of $14 \alpha$-methyl sterols in fungi. Fungicidal activity at high concentrations results from a direct physiochemical effect on the fungal cell membrane. As it binds directly to non-sterol lipids on the fungal membrane and interferes with ligands from the intra-cellular contents, thereby causing cell death. It is an effective fungicidal and fungistatic agent. In addition, anti-inflammatory properties have been described by reducing cytokine secretion from activated lymphocytes, histamine release from mast cells and release of $\mathrm{PGE}_{2}$, all of which control the inflammatory component of dermatophytosis. ${ }^{19-21}$

PGA showed that complete clinical cure rate i.e. excellent response at the end of "treatment phase" was highest with topical sertaconazole $2 \%$ cream $(93.75)$ as compared to clotrimazole $1 \%$ cream $(74.47 \%)$. Complete clinical cure was observed with both the trial drugs at the end of "follow-up phase." A study by Sharma et al., has shown that the sertaconazole produced $62.3 \%$ clearance at the end of 2 weeks. ${ }^{22}$ In the study by Alomar et al., $95.6 \%$ clinical cure rate was seen at the end of treatment with sertaconazole. ${ }^{23}$

Mycological assessment with $\mathrm{KOH}$ mount showed that at the end of "treatment phase," 94\% patients treated with sertaconazole $2 \%$ cream and $62 \%$ patients who received clotrimazole $1 \%$ cream were negative for fungal elements. This proves topical sertaconazole $2 \%$ cream to be superior in mycological cure, followed by clotrimazole $1 \%$ cream. However at the end of follow-up phase complete mycological cure $(100 \%)$ was observed with both the therapies which confirmed absence of recurrence and relapse of tinea corporis. Schopf et al. reported mycological cure rate of $91 \%$ with clotrimazole solution in the treatment of tinea pedis. ${ }^{24}$ Savin and Jorizzo reported sertaconazole $2 \%$ cream showed $70.3 \%$ mycologic cure in patients of tinea pedis. ${ }^{25}$

In this study, we found only one ADR related to treatment. One patient from sertaconazole group during the $1^{\text {st }}$ week reported this. It was burning the sensation at the site of application of sertaconazole, which was of mild grade and lasted only for three days. It did not require any stoppage of medication, shift to another therapy or withdrawal of the patient from the trial. Sharma et al. have reported five patients in the sertaconazole group and nine in the miconazole group developing mild to moderate adverse events. ${ }^{22}$ del Palacio et al. have reported premature termination of their trial due to adverse effects, which were $26.7 \%$ with clotrimazole $1 \%$ cream in candida and dermatophyte skin infections. ${ }^{26}$

For pharmacoeconomic analysis, treatment modality having less cost-effectiveness ratio is considered as superior. It was observed that the CER was significantly higher in sertaconazole $2 \%$ cream when compared to clotrimazole 
$1 \%$ cream at both the follow ups. Thus, it suggests that clotrimazole $1 \%$ cream is cost-effective over sertaconazole $2 \%$ cream in the treatment of tinea corporis. No literature on cost-effectiveness of topical clotrimazole $1 \%$ cream and sertaconazole $2 \%$ cream is reported.

\section{Limitations}

Results of the present study cannot be generalized as this was an open labeled (non-blinded) study with smaller sample size. Furthermore, diagnosis of tinea corporis was purely on the basis of clinical examination and microscopic finding of $\mathrm{KOH}$ mount. We did not identify the causative organism for the tinea corporis by culture sensitivity. More studies with larger size in future are needed.

\section{CONCLUSIONS}

Response to the topical monotherapy with clotrimazole $1 \%$ cream and sertaconazole $2 \%$ cream was safe, effective and well tolerated in the treatment of mild to moderate tinea corporis. Treatment with sertaconazole $2 \%$ cream was early in the onset, required shorter duration of therapy and with tolerable side-effects. Hence, sertaconazole $2 \%$ cream should be preferred as a first line topical monotherapy, followed by clotrimazole $1 \%$ cream. However, topical clotrimazole $1 \%$ cream was cost-effective. Further studies are needed to support the findings of the present study.

\section{Funding: No funding sources}

Conflict of interest: None declared

Ethical approval: The study was approved by the Institutional Ethics Committee

\section{REFERENCES}

1. Mohanty JC, Mohanty SK, Sahoo RC, Sahoo AS, Praharaj $\mathrm{CH}$. Incidence of dermatophytosis in Orissa. Indian J Med Microbiol. 1998;16:78-80.

2. Singh S, Beena PM. Profile of dermatophyte infections in Baroda. Indian J Dermatol Venereol Leprol. 2003;69(4):281-3.

3. Alston SJ, Cohen BA, Braun M. Persistent and recurrent tinea corporis in children treated with combination antifungal/ corticosteroid agents. Pediatrics. 2003;111(1):201-3.

4. Greenberg HL, Shwayder TA, Bieszk N, Fivenson DP. Clotrimazole/betamethasone diproprionate: a review of costs and complications in the treatment of common cutaneous fungal infections. Pediatr Dermatol. 2002;19(1):78-81.

5. Stary A, Soeltz-Szoets J, Ziegler C, Kinghorn GR, Roy RB. Comparison of the efficacy and safety of oral fluconazole and topical clotrimazole in patients with candida balanitis. Genitourin Med. 1996;72(2):98-102.

6. Sobel JD, Brooker D, Stein GE, Thomason JL, Wermeling DP, Bradley B, et al. Single oral dose fluconazole compared with conventional clotrimazole topical therapy of Candida vaginitis. Fluconazole Vaginitis Study Group. Am J Obstet
Gynecol. 1995;172:1263-8.

7. Carrilo-Muñoz AJ, Tur C, Torres J. In-vitro antifungal activity of sertaconazole, bifonazole, ketoconazole, and miconazole against yeasts of the Candida genus. J Antimicrob Chemother. 1996;37(4):815-9.

8. Borelli C, Klövekorn G, Ernst TM, Bödeker RH, Korting HC, Neumeister C. Comparative study of $2 \%$ sertaconazole solution and cream formulations in patients with tinea corporis, tinea pedis interdigitalis, or a corresponding candidosis. Am J Clin Dermatol. $2007 ; 8(6): 371-8$

9. Wolverton SE. Comprehensive Dermatologic Drug Therapy. Volume 24. Philadelphia: WB Saunders Company; 2001: 501-3.

10. Long CC, Finlay AY. The finger-tip unit - a new practical measure. Clin Exp Dermatol. 1991;16(6):444-7.

11. Cohen DJ, Reynolds MR. Interpreting the results of cost-effectiveness studies. J Am Coll Cardiol. 2008;52(25):2119-26.

12. Kanwar AJ, Mamta, Chander J. Superficial fungal infections. In: Valia RG, Valia AR, editors. IADVL Textbook and Atlas of Dermatology. 2nd Edition. Mumbai: Bhalani Publishing House; 2001: 215-58.

13. Bindu V, Pavithran K. Clinico-mycological study of dermatophytosis in Calicut. Indian J Dermatol Venereol Leprol. 2002;68(5):259-61.

14. Peerapur BV, Inamdar AC, Pushpa PV, Srikant B. Clinico mycological study of dermatophytosis in Bijapur. Indian J Dermatol Venerol Leprol. 2004;22:273-74.

15. Vidhya Lakshmi CP, Bengalorkar GM, Kumar VS. Clinical efficacy of topical terbinafine versus topical luliconazole in treatment of tinea corporis/Tinea cruris patients. Br J Pharm Res. 2013;3(4):1001-14.

16. Banerjee M, GhoshAK, Basak S, Das KD, Gangopadhyay DN. Comparative evaluation of effectivity and safety of topical amorolfine and clotrimazole in the treatment of tinea corporis. Indian J Dermatol. 2011;56(6):657-62.

17. Suschka S, Fladung B, Merk HF. Clinical comparison of the efficacy and tolerability of once daily Canesten with twice daily Nizoral (clotrimazole $1 \%$ cream vs. ketoconazole $2 \%$ cream) during a 28 -day topical treatment of interdigital tinea pedis. Mycoses. 2002;45(3-4):91-6.

18. Jerajani H, Janaki C, Kumar S, Phiske M. Comparative assessment of the efficacy and safety of sertaconazole (2\%) cream versus terbinafine cream $(1 \%)$ versus luliconazole (1\%) cream in patients with dermatophytoses: a pilot study. Indian J Dermatol. 2013;58(1):34-8.

19. Pfaller MA, Sutton DA. Review of in vitro activity of sertaconazole nitrate in the treatment of superficial fungal infections. Diagn Microbiol Infect Dis. 2006;56(2):147-52.

20. Carrillo-Muñoz AJ, Quindós G, Del Valle O, Santos P, Giusiano G, Guardia C, et al. In vitro antifungal activity of sertaconazole nitrate against recent isolates of onychomycosis causative agents. J Chemother. 2008;20(4):521-3.

21. Sur R, Babad JM, Garay M, Liebel FT, Southall MD. Antiinflammatory activity of sertaconazole nitrate is mediated via activation of a p38-COX-2-PGE2 pathway. J Invest Dermatol. 2008;128(2):336-44.

22. Sharma A, Saple DG, Surjushe A, Rao GR, Kura M, Ghosh S, et al. Efficacy and tolerability of sertaconazole nitrate $2 \%$ cream vs. miconazole in patients with cutaneous dermatophytosis. Mycoses. 2011;54(3):217-22.

23. Alomar C, Bassas S, Casas M, Crespo V, Ferrándiz $\mathrm{C}$, Fonseca E, et al. Multi-centre double-blind trial on 
the efficacy and safety of sertaconazole $2 \%$ cream in comparison with miconazole $2 \%$ cream on patients suffering from cutaneous mycoses. Arzneimittelforschung. 1992;42(5A):767-73.

24. Schopf R, Hettler O, Bräutigam M, Weidinger G, Kaben U, Mayser P, et al. Efficacy and tolerability of terbinafine 1\% topical solution used for 1 week compared with 4 weeks clotrimazole $1 \%$ topical solution in the treatment of interdigital tinea pedis: a randomized, double-blind, multicentre, 8-week clinical trial. Mycoses. 1999;42(5-6):415-20.

25. Savin R, Jorizzo J. The safety and efficacy of sertaconazole nitrate cream $2 \%$ for tinea pedis. Cutis. 2006;78(4):268-74.

26. del Palacio A, Ortiz FJ, Pérez A, Pazos C, Garau M, Font E. A double-blind randomized comparative trial: eberconazole
$1 \%$ cream versus clotrimazole $1 \%$ cream twice daily in Candida and dermatophyte skin infections. Mycoses. 2001;44(5):173-80.

doi: $10.5455 / 2319-2003 . i j b c p 20150214$

Cite this article as: Khan HS, Dudhgaonkar S,

Bende MM, Wankhede S. Comparison of efficacy, safety and cost-effectiveness of clotrimazole $1 \%$ cream and sertaconazole $2 \%$ cream in patients suffering from of mild to moderate tinea corporis, attending tertiary care hospital out-patient department: a randomized, openlabeled, comparative, parallel group trial. Int J Basic Clin Pharmacol 2015;4:75-81. 